Original Research

\title{
Glen Canyon Dam Operation Effects on Rainbow Trout Habitat and Population Status
}

\author{
Weiwei Yao ${ }^{1,2 *}$, Yuansheng Chen' ${ }^{1}$ Xinlin $\mathrm{He}^{3,4}$ \\ ${ }^{1}$ Key Laboratory of Environmental Remediation, Institute of Geographic Sciences and Natural Resources Research, \\ China Academy of Sciences, Beijing, 100101, China \\ ${ }^{2}$ Key Laboratory of Carrying Capacity Assessment for Resource and Environment, Ministry of Land \\ and Resources, Institute of Geographic Sciences and Natural Resource Research, \\ the Chinese Academy of Sciences, Beijing, 100812, China \\ ${ }^{3}$ College of Water Conservancy \& Architectural Engineering, Shihezi University, \\ Shihezi, Xinjiang, 832000, China \\ ${ }^{4}$ Key Laboratory of Modern Water-saving Irrigation of Xinjiang Construction Corps, \\ Shihezi, Xinjiang, 832000, China.
}

Received: 28 April 2017

Accepted: 1 June 2017

\begin{abstract}
A dynamic habitat and population model has been developed and applied to the tailwater below Glen Canyon Dam to estimate the dam operation's effects on rainbow trout (Oncorhynchus mykiss) habitat and population dynamics. Water depth, flow temperature, flow velocity, and substrate types were used as the suitability parameters and to evaluate these indicators. Historic hydraulic data from 1991 to 2009 were analyzed to determine the minimum, mean, and maximum flow rates that were used to represent the habitat suitability index (HSI) and overall suitability index (OSI) of the rainbow trout fry, adult, and spawning life stages, respectively. Fish abundance and the simulation results were also compared with observed fish numbers. Results indicated that under the historic dam operation, the habitat suitability level in the Colorado River was not suitable for fry and spawning rainbow trout, but very suitable for adult rainbow trout. It is indicated that high HSI levels do not mean high fish abundance. It can also be seen that overall rainbow trout abundance decreased during the period 1991 to 2009.
\end{abstract}

Keywords: habitat and population model, rainbow trout population, habitat suitability index, dam operation

*e-mail: weiweiyao@igsnrr.ac.cn 


\section{Introduction}

Research has proven that alterations of flow regimes in regulated rivers influence the abundance of fish species [1-2]. Many studies have demonstrated that fluctuations of fish populations might be associated with lengthspecific responses to dam operations [3-4]. However, very few references have been made to the effects of river management action, and the role of dams in influencing fish habitat and population are poorly understood. With the development of numerical simulation for aquatic ecosystems, attention has become focused on the influence of dams on fish habitat and populations [5-7]. Understanding river habitat and fish populations could help river managers regulate river ecology and fish populations.

The population model, as its name indicates, is used to calculate both the temporal and spatial variations of fish populations. The population model used here helps in understanding how flow regimes affect the fish population. In order to analyze and to determine how characteristics of the fish population change with time, the revised logistic population model is proposed based on the concepts in 'InSTREAM' and 'Salmon' [8]. This population model is a mathematical model that provides a manageable way of understanding how fish species' numbers change over time with physical variables, and with individuals of their own species [9].

This paper aims to simulate the rainbow trout (Oncorhynchus mykiss) habitat and abundance in the Colorado River, which is the tailwater below Glen Canyon Dam, from 1991 to 2009 based on the habitat model and population models developed by the authors. This paper: 1) proposed a model system used to simulate fry, adult, and spawning rainbow trout habitats from 1991 to 2009; 2) predict the fry, adult, and spawning rainbow trout population number changes and validate it with observed data; and 3) draw a fish population density distribution map and use it to assesses the effects of the Glen Canyon Dam operation on habitat and population.

\section{Materials and Methods}

$$
\text { Study Areas }
$$

Glen Canyon Dam is located on the Colorado River in northern Arizona in the United States. The tailwater below the dam is located in Arizona and is $25 \mathrm{~km}$ long (Fig. 1). The historical flow rate records from 1991 to 2009 were used to determine the minimum, mean, and maximum flow rates. The dam flow rate is $426 \mathrm{~m}^{3} / \mathrm{s}$ with a mean depth of $6.5 \mathrm{~m}$ and a width of $150 \mathrm{~m}$. From 1991 to 1995 the annual discharge was around $330 \mathrm{~m}^{3} / \mathrm{s}$ and from 1996 to 2001 the annual discharge was more than $400 \mathrm{~m}^{3} / \mathrm{s}$. Thereafter, the discharge experienced a decrease [10-12]. Based on the historical discharge rates, the years 1991, 1997, and 2005 were used to represent the minimum, maximum, and average flow rates, respectively.

This river branch has had long-term fish monitoring since the 1980s by the U.S. Geological Survey's Grand Canyon Monitoring and Research Center, a federal advisory committee named the Glen Canyon Dam Adaptive Management Program and Arizona Game and Fish Department, in order to protect and mitigate adverse impacts on the fish species downstream from the dam. The study area has a diverse variety of freshwater fish, such as rainbow trout that coexist with flannelmouth suckers (Catostamus latipinnis) and common carp (Cyprinus carpio). Rainbows are the most abundant nonnative fish in the river and the cold water released from the bottom of the reservoir provides a suitable temperature for them to survive. Electrofishing has been used to sample the fish in the study area and rainbow trout were sampled two to four times per year [11]. Based on survey data, rainbows numbers were obtained to show the fish number changes in the monitoring area. The fish caught were used
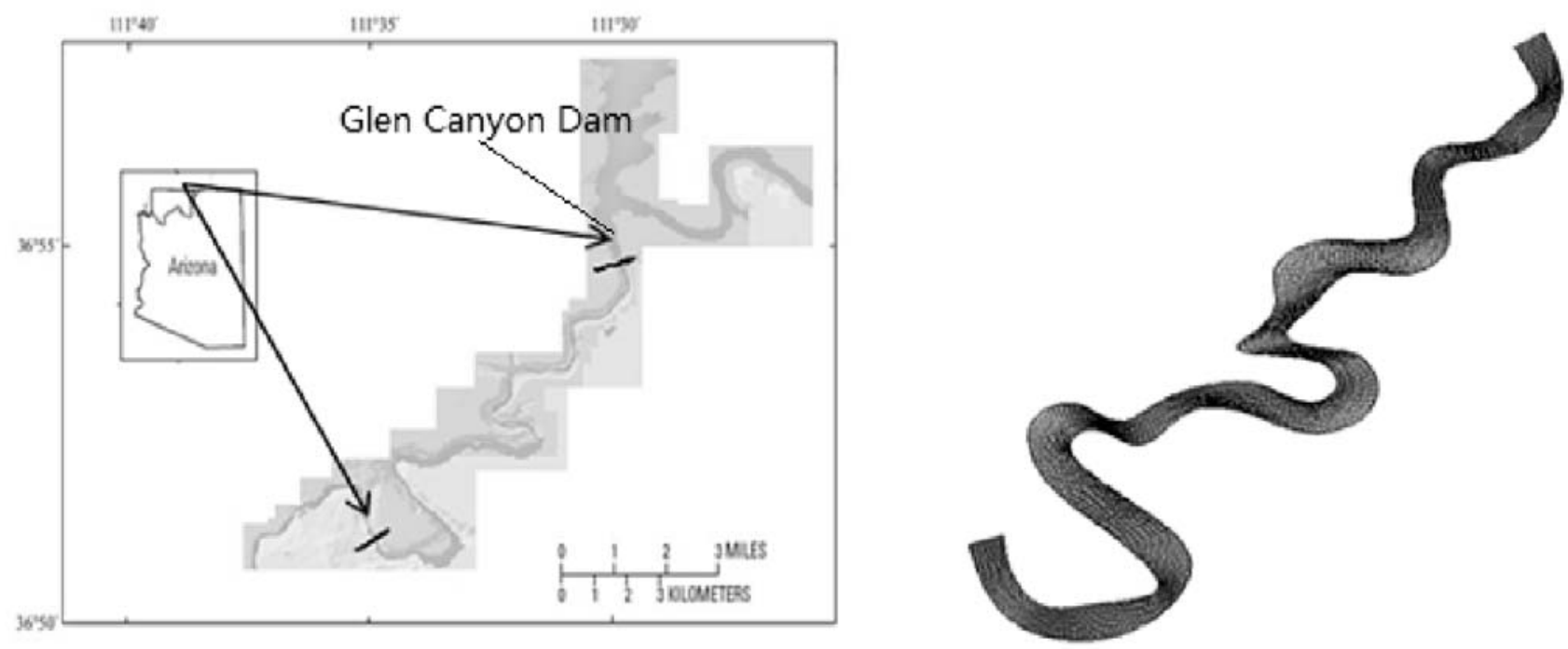

Fig. 1. Study area on Colorado River (left side) and the computational domain (right side). 


\section{Hydrodynamic,}

Heat transfer,

Sediment model.

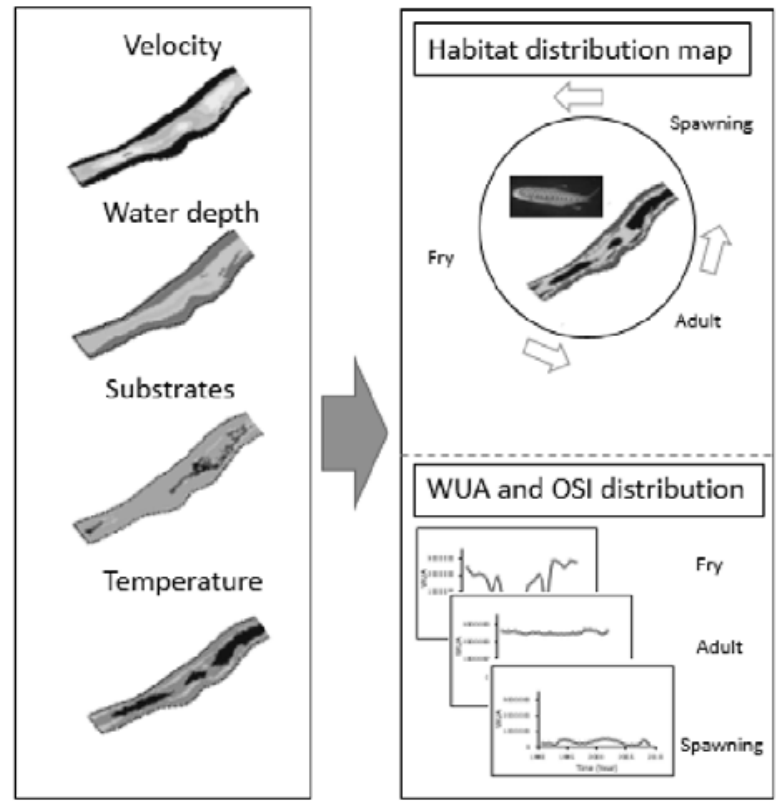

Population model

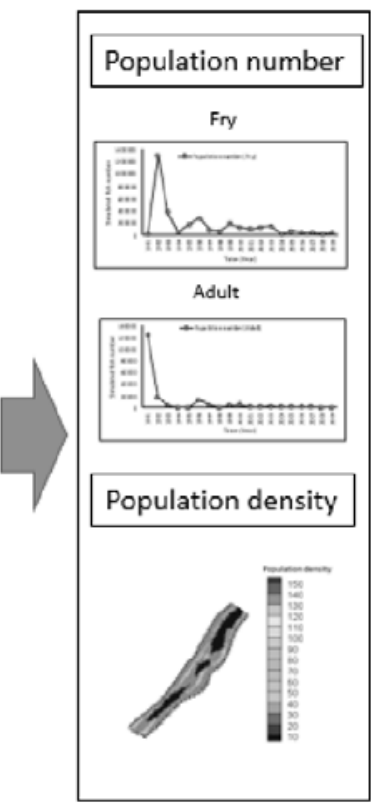

Populatin structure

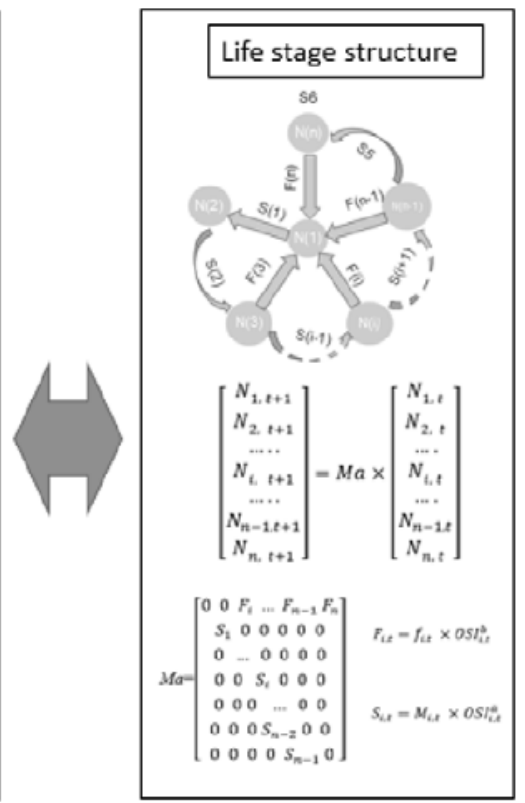

Fig. 2. Flowchart of the model system for rainbow trout (Oncorhynchus mykiss).

to estimate the numbers of rainbow in each life stage [7, 9].

\section{Model System Components and Model Set Up}

The model system contains four components (Fig. 2):

- Dynamic hydraulics and heat transfer model

- Sediment transport model

- Physical habitat model

- Fish population model

The results of the hydraulic, heat transfer, and physical habitat models are combined to determine the population model for the target species in the study area as well as to assess the temporal variation of the fish population.

The equations governing water flow within the river are the Reynolds-averaged Navier-Stokes equations [13]. The heat transfer equation and the $\mathrm{k}-\varepsilon$ turbulence model also were integrated inside the equations. The modified semi-empirical transport equation Meyer-Peter Müller formula is used to calculate the sediment transport capacity. The bed level change is due to deposition and erosion, which are also based on empirical equations. The sediment continuity equation, also known as Exner equation, is used to calculate the bed load effects on river bed deformation [14]. The habitat models are used to predict the distribution of rainbow trout in a branch of Lees Ferry based on the information of the preference curves. The habitat model defines three important indices: the value of HSI range from 0 to 1 , the definition of ideal HSI is between 0.7 to 1 , and an unsuitable HSI value is lower than 0.3 .

$$
\begin{gathered}
H S I=\sqrt[4]{S I_{d} \times S I_{v} \times S I_{s} \times S I_{T}} \\
W U A=\sum_{i=1}^{M} A_{i} H S I_{i} \\
\text { OSI }=\frac{\sum_{i=1}^{M} A_{i} H S I_{i}}{\sum_{i=1}^{M} A_{i}} \times 100 \%
\end{gathered}
$$

...where $\mathrm{HSI}_{\mathrm{i}}$ is the habitat suitability index of a spatial mesh volume $i ; \mathrm{SI}_{\mathrm{d}}, \mathrm{SI}_{\mathrm{v}}, \mathrm{SI}_{\mathrm{s}}$, and $\mathrm{SI}_{\mathrm{T}}$ are suitability indexes with respect to water depth, velocity, substrate, and flow temperature; and WUA is the weighted usable areas while OSI is the overall suitability index.

In order to analyze and to determine how characteristics of the fish population change with time, the age stage structured population model based on habitat model is proposed. Our age stage population model is a mathematical model that divides the age into fry/larvae, adult, and spawning life stages based on fish length. The spawning life stage is used to adjust fish fertility rate.

Aforementioned equations describe the population structure. The population dynamics can be described with the following equation: 


$$
\left[\begin{array}{l}
\mathrm{N}_{1, t+1} \\
\mathrm{~N}_{2, t+1} \\
\cdots \cdots \\
\mathrm{N}_{\mathrm{i}, \mathrm{t}+1} \\
\cdots \cdots \\
\mathrm{N}_{\mathrm{n}-1, \mathrm{t}+1} \\
\mathrm{~N}_{\mathrm{n}, \mathrm{t}+1}
\end{array}\right]=\mathrm{Ma} \times\left[\begin{array}{l}
\mathrm{N}_{1, \mathrm{t}} \\
\mathrm{N}_{2, \mathrm{t}} \\
\cdots \cdots \\
\mathrm{N}_{\mathrm{i}, \mathrm{t}} \\
\cdots \cdots \\
\mathrm{N}_{\mathrm{n}-1, \mathrm{t}} \\
\mathrm{N}_{\mathrm{n}, \mathrm{t}}
\end{array}\right]
$$

$$
\mathrm{Ma}=\left[\begin{array}{ccccccc}
0 & 0 & \ldots & \mathrm{F}_{i} & \ldots & F_{n-1} & F_{n} \\
S_{1} & 0 & 0 & 0 & 0 & 0 & 0 \\
0 & S_{2} & 0 & 0 & 0 & 0 & 0 \\
0 & 0 & \ldots & 0 & 0 & 0 & 0 \\
0 & 0 & 0 & S_{i} & 0 & 0 & 0 \\
0 & 0 & 0 & 0 & \ldots & 0 & 0 \\
0 & 0 & 0 & 0 & 0 & S_{n} & 0
\end{array}\right]
$$

$$
\mathrm{F}_{i, t}=f_{i, t} \times O S I_{i, t}^{b} ; \mathrm{S}_{i, t}=M_{i, t} \times O S I_{i, t}^{a}
$$

... where $\mathrm{N}_{\mathrm{n}, \mathrm{t}+1}$ and $\mathrm{N}_{\mathrm{n}, \mathrm{t}}$ are the population vectors on the time steps $\mathrm{t}+1$ and $\mathrm{t}$, respectively; $\mathrm{n}$ is the age of the fish; $M$ is mortality rate; $M a$ is the matrix representing agespecific fertility; $\mathrm{t}$ is time; $a$ and $b$ are the parameters equal to 0.25 and $1.1 ; F$ is the adjusted birth rate; $f$ is the birth rate; and $S$ is the survival rate (the other parameters are the same as noted before).

Age-specific-based mortality and birth rates of population were obtained from Pauly and adjusted by equation 5 [15]. For the case of the rainbow trout in this study, we define the rainbow trout length as longer than $405 \mathrm{~mm}$ as adult life stage, its lifespan equal to 6 years and the maturity range between 3 to 6 years. The corresponding fish life cycle graph is mathematically equivalent to the matrix, but provides a more intuitive and appealing version of the fish life cycle. In the life cycle graph, circles represent stages or states. Arrows connecting the circles represent the survival rates from one stage to the next (Fig. 2).

For the model setup, the inlet boundary, outlet boundaries, and the side boundary conditions are used. The third-order deferred correction QUICK scheme is implemented for the convection term and secondorder central difference scheme for dispersion terms. The discretized equations are solved by a line-by-line procedure combining the tri-diagonal matrix algorithm and the successive over relaxation. More details on the numerical solution can be obtained from Chung [16].

\section{Results and Discussion}

The simulation domain is shown in Fig. 1, which covers the tailwater below Glen Canyon Dam and represents an area of $4 \times 10^{6} \mathrm{~m}^{2}$. Flow velocity, temperature distribution, and sediment transport distribution has been displayed for the years 1991, 1997, 2005, and 2009. The distributions
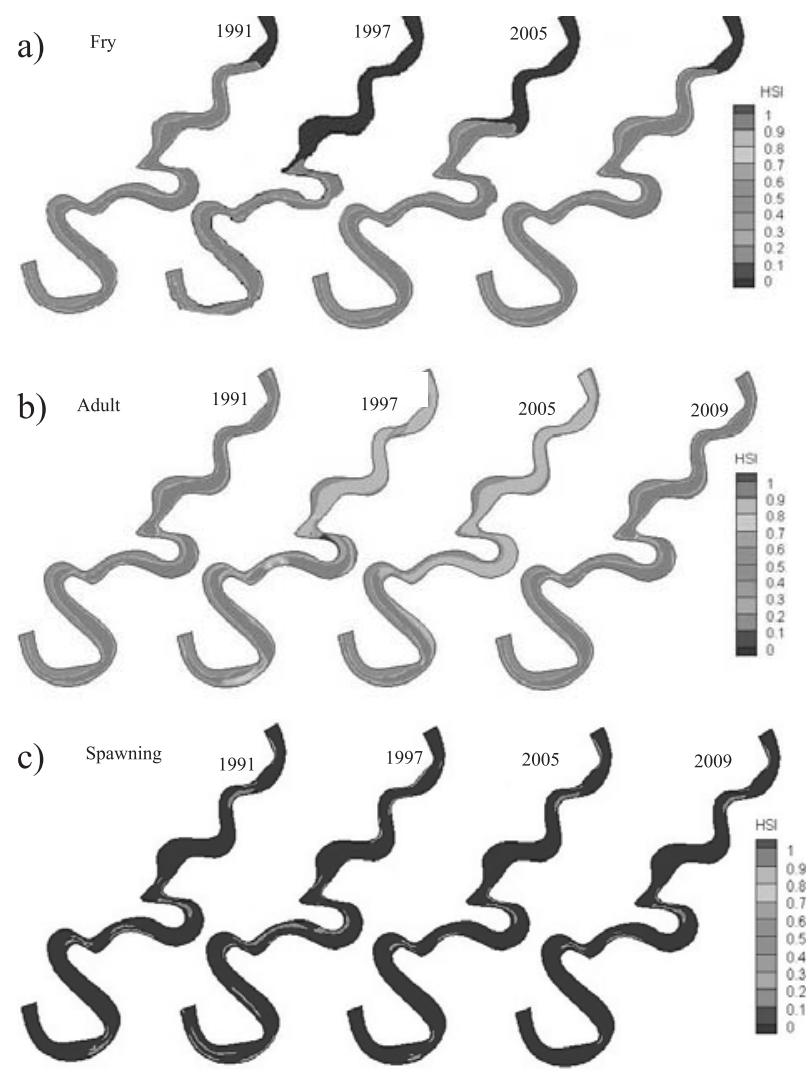

Fig. 3. Habitat suitability index distributions for fry, adult, and spawning fish in 1991, 1997, 2005, and 2009.

of WUA and OSI are presented for all the years by line graphs. Population distribution in the tailwater of the dam is presented to illustrate the rainbow trout density in our simulation. The adult fish simulation results are compared with the surveyed fish data.

Flow velocity, water depth, temperature distribution, and bed deformation in the years 1991, 1997, 2005, and 2009 were simulated. From the simulation results we come to know that during the simulation period, the large-scale morphological change happened in the middle of the river (erosion pattern) and the left side riverbank (deposition pattern). Comparing the initial state (1991) and the bed level in 1997, 2005, and 2009, we can recognize that the right side of the river shows no significant deposition or erosion patterns, and in active areas the maximum erosion depth is $3.2 \mathrm{~m}$ and maximum deposition depth is $2.8 \mathrm{~m}$.

According to the USGS substrates type survey and the preference curves criterion of rainbow trout, the initial suitability index associated with substrates is equal to $0.2,0.8$, and 1 for fry, adult, and spawning rainbow trout, respectively. From the simulation, it is noted that after long-term sediment transport simulation, the suitability index for the substrates is kept unchangeable. In contract, the erosion and deposition in the river bed cause water depth change that affects target fish suitability in the study river.

Fig. 3 shows the habitat suitability index at the study river for fry, adult, and spawning stages in the years 1991, 1997,2005 , and 2009. It is noted that downstream of the 


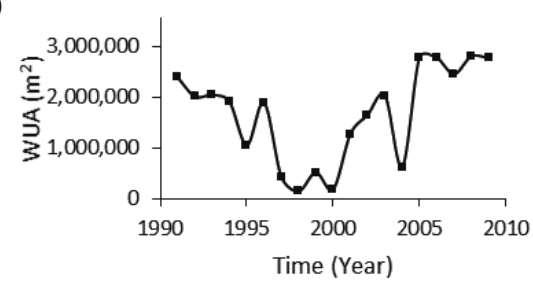

b)

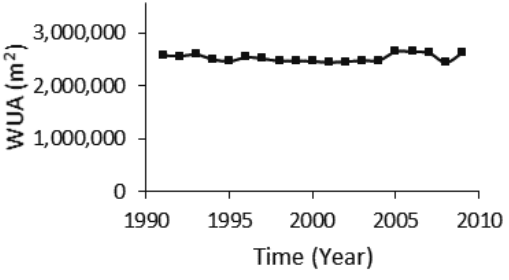

c)

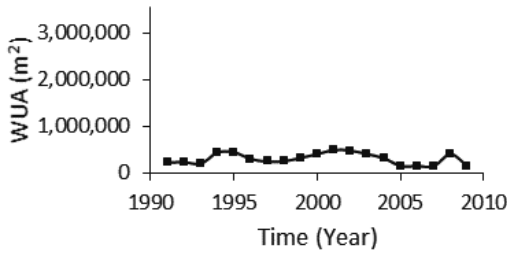

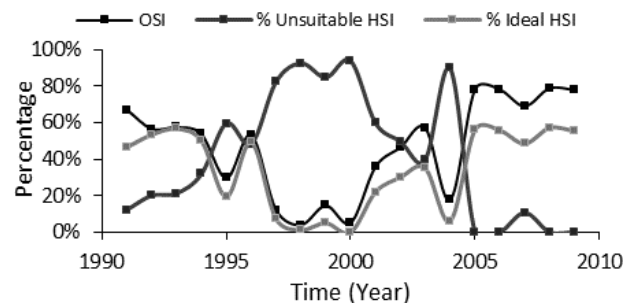
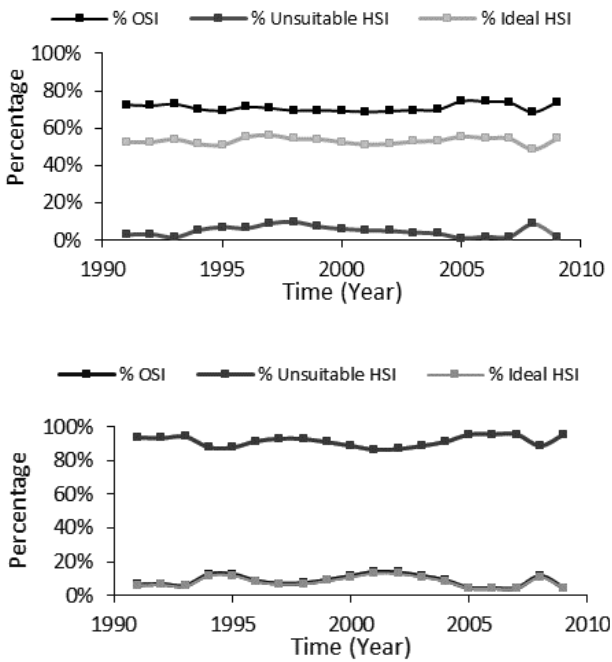

Fig. 4. The WUA and OSI values for fry (top), adult (middle), and spawning (bottom) rainbow trout, 1990-2009.

a) $1,400,000$
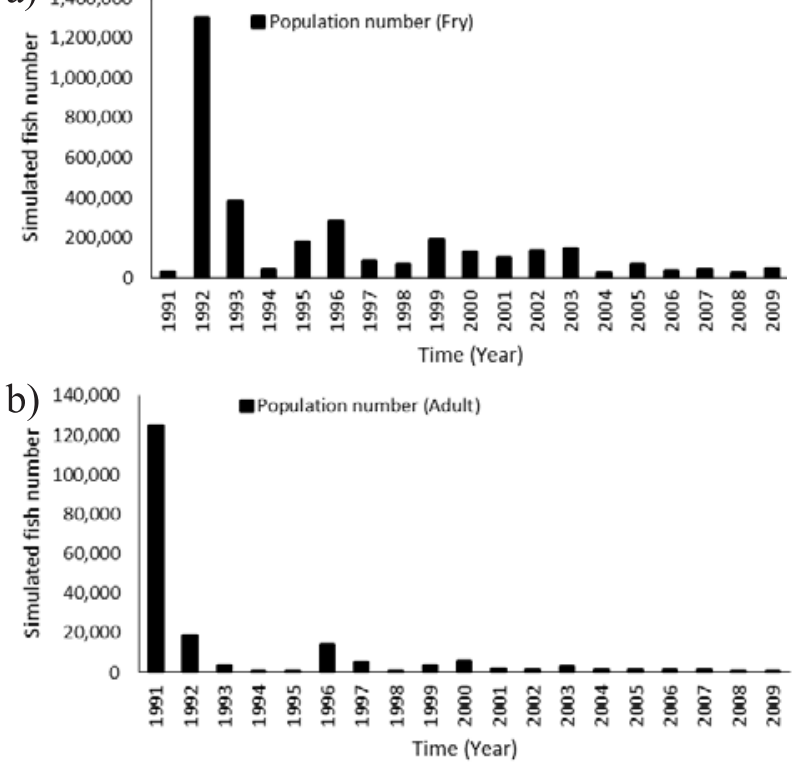

c)

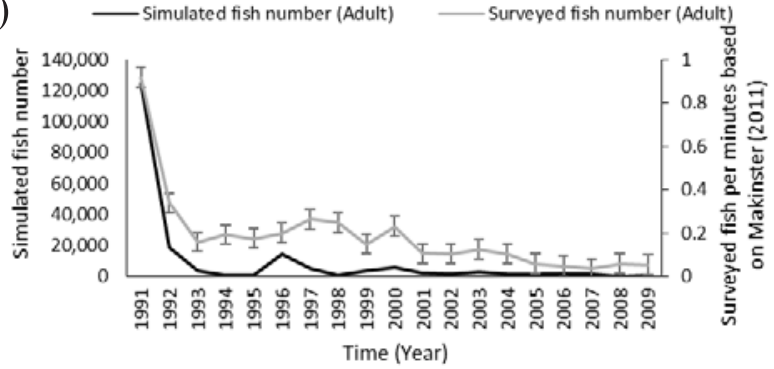

Fig. 5. Simulated fry and adult rainbow trout population numbers, and a comparison between simulated and surveyed fish numbers. river has a higher habitat suitability index than upstream, and the middle of the river has higher habitat suitability than the sides of the river for fry rainbow trout. The reason for this is because the upstream temperature is severely affected by the low temperature on the bottom of the reservoir. We also come to know that the majority domain of the river has a good habitat suitability index except for the narrowed portion of the river, which presented low suitability for adult rainbow trout in 1991. The other years also show a similar trend. In contrast, most of the river areas are unsuitable for the spawning stage of rainbow trout, and only several pieces of small areas scattered in the riverside are suitable.

It is from Fig. 4 that the WUA and OSI have exactly the same trends for all life stages from 1991 to 2009 . For the fry rainbow trout, the OSI decreased from $70 \%$ in 1991 to $5 \%$ in 1998 - except for 1996, when there was a short increase. After that the OSI experienced a dramatic increase from 2000 to 2004 , going from $6 \%$ to $58 \%$, and then decreased dramatically again in 2004. After that the OSI rose again and reached $80 \%$. The proportion of ideal HSI also showed the same trends with OSI while the proportion of unsuitable HSI show the opposite trend with OSI. For the adult rainbow trout, the OSI was maintained at the level of $70 \%$ and the percentage of Ideal HSI kept within $52 \%$, while the percentage of unsuitable HSI fluctuated between $1 \%$ and $10 \%$ from 1991 to 2009 . For the spawning rainbow trout, the OSI and the proportion of Ideal HSI had exactly the same values that were below $15 \%$ in all those years, and the percentage of unsuitable HSI was over $85 \%$ from 1991 to 2009 . 


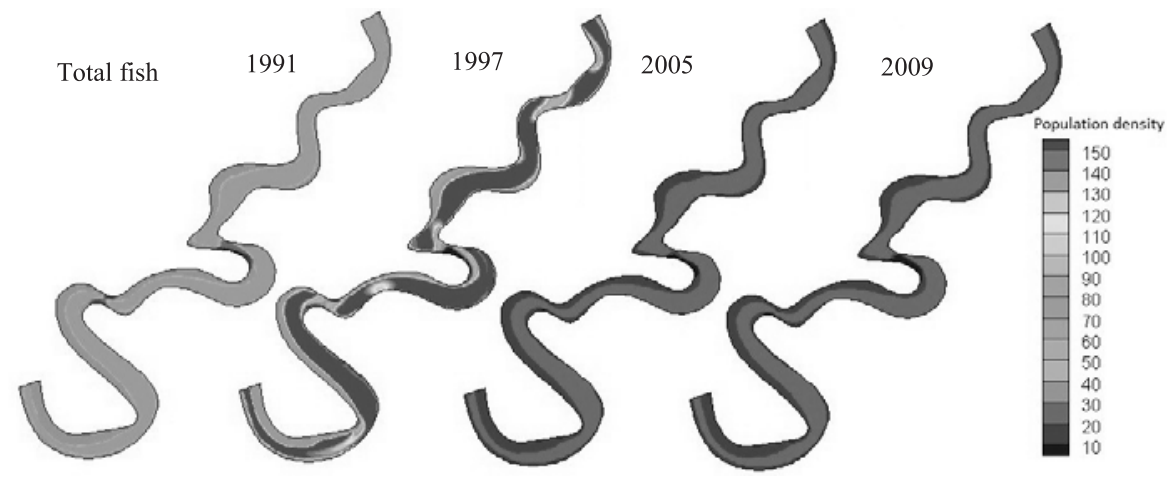

Fig. 6. Rainbow trout abundance maps in 1991, 1997, 2005, and 2009.

The dynamics of fish abundance are analyzed based on the calculated results of the population model. The total rainbow trout fish number at the beginning of the simulation was $\mathrm{P}_{1991}=3.5 \times 10^{5}$ (determined by USGS). The proportion of the different life stages is in accordance with the survey, which is $\mathrm{P}_{\mathrm{L}}=225193$ and $\mathrm{P}_{\mathrm{A}}=124806$. The simulation results and a comparison between survey and simulated fish population are shown in Fig. 5. It is noted that the fry rainbow trout shows a sharp increase in number, and then shows a decreasing trend with a period of steady increase in 1995, 1996, and 1999. From the simulation results, it is also noted that the number of adult rainbow trout decreases during the simulation period. Comparing simulation results with the survey data of the USGS for rainbow trout longer than $405 \mathrm{~mm}$, we can see that there is considerably good agreement.

The simulated results of the distribution of adult rainbow trout in 1991, 1997, 2005, and 2009 are shown in Fig. 6. It is clear that rainbow trout density varies considerably along the river. Generally, the middle of the river has higher fish density than the riverbank. The simulation results also indicate a low density of rainbow trout in the narrow areas with high flow velocities. A comparison of the habitat distribution and the fish population distribution in 1991, 1997, 2005, and 2009 indicate that high HSI does not mean high fish abundance.

Our simulations show reasonable results and support the accuracy and effectiveness of the model system. In order to determine the main reasons attributed to the fluctuation of fish populations in the tailwater of Glen Canyon Dam, a more detailed study of the rainbow trout fish in this region was undertaken. For the rainbow trout species, as discussed in previous studies, flow discharge or velocity is the main factor influencing population. This is consistent with previous research [17-18].

It is recognized that fish population sustainability and regrowth can be assessed by considering the internal and external recovery processes, and in this study dam operation is a primary driving variable that influences the rainbow trout population. Previous research has investigated fish population recovery after habitat alteration [19], flood effects [20], and pesticide stress
[21]. However, different species displayed different recovery times, and even the same species show different regrowth patterns in different streams. In the current study, suitable habitat is a key variable that affects fish population numbers in the tailwater of Glen Canyon Dam. We provide habitat and population model simulation results to explain that flow discharge provides conditions that support fluctuation of rainbow trout and prove that regrowth and abundance of rainbow trout is possible. Our simulation results support the conclusion that dam operations based on fish habitat and the population model are a very appropriate approach for eco hydraulic management.

It is believed that linking suitability preference curves of various fish species to a hydrodynamic model permitted a better understanding of parameters affecting ecological diversity and habitat creation. It is also noted that the population model investigations are a powerful tool in determining dam operations and sustainable conservation strategies - especially to simulate and predict quantitative changes in fish populations and their exploitation. In addition, it is a useful tool for the development of a stable fish population and could be used to evaluate the river restoration effects on fish numbers. This method is useful both in the design process and as a tool for presenting possible solutions and their effects on fish in rivers. Further development should be considered, and a considerable amount of work of collecting data is required to establish growth and mortality models and to validate the population model system, including hydro morphological and fish habitat models. However, with an increased interest in habitat and population model improvement, the methods will probably be better in the future and will further improve the results through more experience and more data. Important areas for future research and development are in the application of the habitat model, and testing and verifying hydraulic and environmental methods.

\section{Conclusions}

In this paper, a fish population model has been integrated into a fish habitat model to investigate the Glen Canyon Dam's effects on rainbow trout abundance. 
Age structure matrice, habitat suitability index, and overall suitability index were considered in this model. Velocity, water depth, and substrate preference curves were integrated into the habitat model to determine the parameters of the population model. Model simulations were undertaken to determine the rainbow trout habitat conditions and populations from 1991 to 2009. Through model prediction, it is noted that the dynamics of fish habitat and fish abundance can be simultaneously simulated. This model can be used to manage the Glen Canyon Dam to maintain rainbow trout riverine populations. Our results also indicate that the approach is a powerful tool in determining dam operations and sustainable conservation strategies.

\section{Acknowledgements}

Our work was financially supported by China's Water Key Project Plan (2016YFC0502004), CCA project (2017.07), National Natural Science Founding (41430861), CAS project (Y6V60222YZ), The National Key Research and Development Program of China (2017YFC0404304), and The Basic Research and Application Program of the Bingtuan (2016AG003).

\section{References}

1. MCMANAMAY R.A., PEOPLES B.K., ORTH D.J., DOLLOFF C.A., MATTHEWS D.C. Isolating causal pathways between flow and fish in the regulated river hierarchy. Canadian Journal of Fisheries and Aquatic Sciences. Jul 7, 72 (11), 1731, 2015.

2. TAYLOR J.M., SEILHEIMER T.S., FISHER W.L. Downstream fish assemblage response to river impoundment varies with degree of hydrologic alteration. Hydrobiologia. May 1; 728 (1), 23, 2014.

3. YAO W., RUTSCHMANN P. SUDEEP. Three high flow experiment releases from Glen Canyon Dam on rainbow trout and flannelmouth sucker habitat in Colorado River. Ecological Engineering. Feb 28; 75, 278, 2015.

4. HARNISH R.A., SHARMA R., MCMICHAEL G.A., LANGSHAW R.B., PEARSONS T.N. Effect of hydroelectric dam operations on the freshwater productivity of a Columbia River fall Chinook salmon population. Canadian Journal of Fisheries and Aquatic Sciences. Feb 25; 71 (4), 602, 2014.

5. YAO W., RUTSCHMANN P., BAMAL S. Modeling of river velocity, temperature, bed deformation and its effects on rainbow trout (Oncorhynchus mykiss) habitat in Lees Ferry, Colorado River. International Journal of Environmental Research. Oct 1; 8 (4), 887, 2014.

6. YI Y., CHENG X., YANG Z., WIEPRECHT S., ZHANG S., WU Y. Evaluating the ecological influence of hydraulic projects: A review of aquatic habitat suitability models. Renewable and Sustainable Energy Reviews. Feb 28; 68748 2017.
7. YAO W. Application of the Ecohydraulic Model on Hydraulic and Water Resources Engineering. Ph.D. Thesis, Technische Universität München, München, Germany, 2016.

8. HARVEY B.C., JACKSON S.K., AND LAMBERSON R. H. InSTREAM: the individual-based stream trout research and environmental assessment model (Vol. 218). US Department of Agriculture, Forest Service, Pacific Southwest Research Station, 2009.

9. YAO W.W., KUMAR V., RUTSCHMANN P. Simulating Dam Effects on River Deformation and Rainbow Trout (Oncorhynchus mykiss) Population Number. CRC press: New York, NY, USA, 2477, 2014.

10. VERNIEU W.S. Effects of the 2008 high-flow experiment on water quality in Lake Powell and Glen Canyon Dam releases, Utah-Arizona: U.S. Geological Survey Open-File Report 2010-1159, 25 p, 2010.

11. MAKINSTER A.S., PERSONS W.R., AVERY L.A., BUNCH A.J. Colorado River fish monitoring in Grand Canyon, Arizona; 2000 to 2009 summary: U.S. Geological Survey Open-File Report 2010-1246, 26 p, 2010.

12. MAKINSTER A.S., PERSONS W.R., AVERY L.A. Status and trends of the rainbow trout population in the Lees Ferry reach of the Colorado River downstream from Glen Canyon Dam, Arizona, 19912009: U.S. Geological Survey Scientific Investigations Report 2011-5015, 17 p, 2011.

13. KAJISHIMA T, TAIRA K. Reynolds-Averaged NavierStokes Equations. InComputational Fluid Dynamics (pp. 237-268). Springer International Publishing, 2017.

14. SCHMEECKLE M.W. Numerical simulation of turbulence and sediment transport of medium sand. Journal of Geophysical Research: Earth Surface. Jun 1; 119 (6), 1240, 2014.

15. PAULY D., MOREAU J., ABAD N. Comparison of agestructured and length-converted catch curves of brown trout (Salmo trutta) in two French rivers. Fisheries Research 22. 3, 197, 1995

16. POZRIKIDIS C. Fluid dynamics: theory, computation, and numerical simulation. Springer, 2016.

17. WANG F., LIN B. Modelling habitat suitability for fish in the fluvial and lacustrine regions of a new Eco-City. Ecological Modelling, 267, 115, 2013.

18. FETHERMAN E.R., WINKELMAN D.L., BAERWALD M.R., SCHISLER G.J. Survival and reproduction of Myxobolus cerebralis-resistant Rainbow Trout introduced to the Colorado River and increased resistance of age-0 progeny. PloS one. May 8; 9 (5), e96954, 2014.

19. HUTCHINGS J.A., POST J.R. Gutting Canada's Fisheries Act: no fishery, no fish habitat protection. Fisheries. Nov 19; 38 (11), 497, 2013.

20. NAGHIBI A., LENCE B. Assessing impacts of high flow events on fish population: Evaluation of risk-based performance measures. Ecological Modelling, 240, 16, 2012.

21. IBRAHIM L., PREUSS T.G., SCHAEFFER A., HOMMEN U. A contribution to the identification of representative vulnerable fish species for pesticide risk assessment in Europe - A comparison of population resilience using matrix models. Ecological Modelling, 2013. 